\title{
Pulmonary Benign Metastasizing Leiomyoma: An Extremely Rare Case
}

\author{
Yetkin AĞAÇKIRAN', Göktürk FINDIK², Leyla N. ÜSTÜN², Koray AYDOĞDU², Sadi KAYA ${ }^{2}$ \\ Department of ${ }^{1}$ Pathology and ${ }^{2}$ Chest Surgery, Atatürk Chest Diseases and Thoracic Surgery Education and Research Hospital, ANKARA, TURKEY
}

Presented at the 6th Thoracic Surgery Congress, April 28 - May 1, 2011 in Antalya, Turkey

\begin{abstract}
Benign metastasizing leiomyoma is typically seen in young premenopausal women after a mean period of 15 years following uterine leiomyoma or hysterectomy surgery. They are usually incidentally seen on chest x-rays and are nodular lesions that appear as bilateral nodules with a benign appearance and consist of smooth muscle proliferation. A 44-year-old female presented at her healthcare institution for backache for the last 9 months. Multiple nodules (largest $15 \mathrm{~mm}$ ) scattered in both lungs and consistent with metastases were detected on computed tomography. The PET-CT results revealed multiple nodular densities with increased metabolic activity (SUVmax: 1.92) in both lungs, with the largest one measuring approximately $15 \mathrm{~mm}$ and located in the lower lobe superior segment of the right lung. A benign metastasizing leiomyoma was diagnosed with open wedge biopsy of the lung. We present this case due to its interesting clinical presentation and rarity and emphasize the pathogenesis.
\end{abstract}

Key Words: Leiomyoma, Uterus, Lung, Metastasis, Lymphatic

\section{INTRODUCTION}

Benign metastasizing leiomyoma (BML) is a rare condition with interesting clinical characteristics. This terminology was first reported in English literature in 1939 by Steiner (1). BML generally occurs in women during their reproductive years. BML is usually associated with uterine leiomyoma and may develop years after a hysterectomy or myomectomy. They are incidentally noticed on chest radiography as bilateral benign lesions proliferating from smooth muscles. Although most commonly seen in the lungs, other sites of involvement have been reported in the literature including lymph nodes, omentum, pelvis, abdomen, mediastinum, vertebra, cranium, skeletal muscle, skin, vena cava inferior, right atrium, breast, trachea, esophagus, liver and adrenal glands $(2,3)$. Patients with pulmonary BML are almost always asymptomatic, though some patients present with cough or breathlessness not affecting pulmonary function. There is no standardized treatment available; treatment options include hormonal manipulation with bilateral oophorectomy or hormonal therapy together with pulmonary nodule resection $(4,5)$.

\section{CASE REPORT}

A 44-year-old woman with a backache for 9 months was referred to our center for further evaluation and treatment of a suspected diagnosis of pulmonary metastasis. Her

(Turk Patoloji Derg 2016, 32:193-195)

Received : 13.03.2012 Accepted : 22.04.2012 computed tomography scan revealed multiple nodules (largest $15 \mathrm{~mm}$ ) scattered in both lungs (Figure 1A,B) and the tru-cut transthoracic biopsy was non-diagnostic. The patient had undergone a myomectomy in 1994 and a total abdominal hysterectomy (adnexal preservation) in 1996 for fibroids. A pelvic USG revealed a $31 \times 18 \mathrm{~mm}$ hypoechoic fusiform mass in the right lateral abdominal wall. PET-CT results, correlated with CT findings, revealed a large nodule in the right lower lobe superior segment with increased activity (SUVmax: 1.92) and another 31x18 mm soft tissue lesion in the right pelvic region with increased metabolic activity (SUVmax: 4.60). In October 2010, a total of 5 nodules, the largest measuring $1.5 \mathrm{~cm}$, were excised from the middle and lower lobe via right thoracotomy and later, in November 2010, a total of 6 nodules, the largest measuring $1.2 \mathrm{~cm}$, were excised via left thoracotomy (Figure 2).

On microscopic examination, a well-circumscribed lesion with compressed adjacent lung parenchyma and interlacing bundles of spindle cells was seen (Figure 3). Anaplasia, mitosis, necrosis, or hemorrhage was not seen. Strong positivity for vimentin, smooth muscle actin, and desmin were detected by immunohistochemical methods. Immunoreactivity for progesterone and estrogen receptors was strongly positive (Figure 4). The proliferative index with Ki-67 was $3 \%$. According to these findings, benign metastasizing leiomyoma was diagnosed. Consequently, in 2011, bilateral

Correspondence: Yetkin AĞAÇKIRAN

Atatürk Göğüs Hastalıkları ve Göğüs Cerrahisi Eğitim ve Araştırma

Hastanesi, Patoloji Kliniği, ANKARA, TURKEY

E-mail: yagackiran@hotmail.com Phone: +90 5327280628 


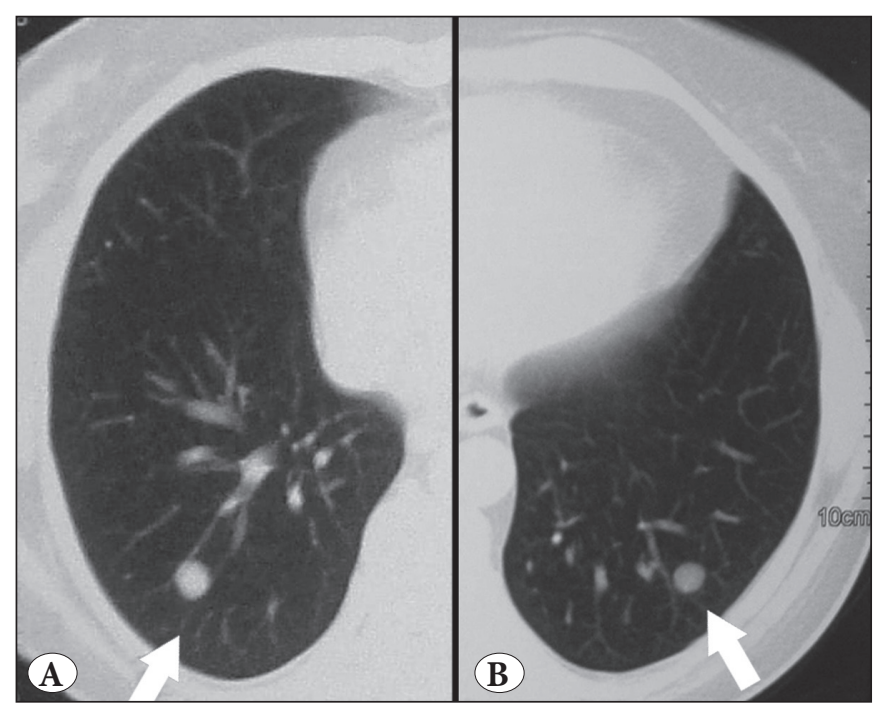

Figure 1A,B: Chest CT showing bilateral separate nodules.

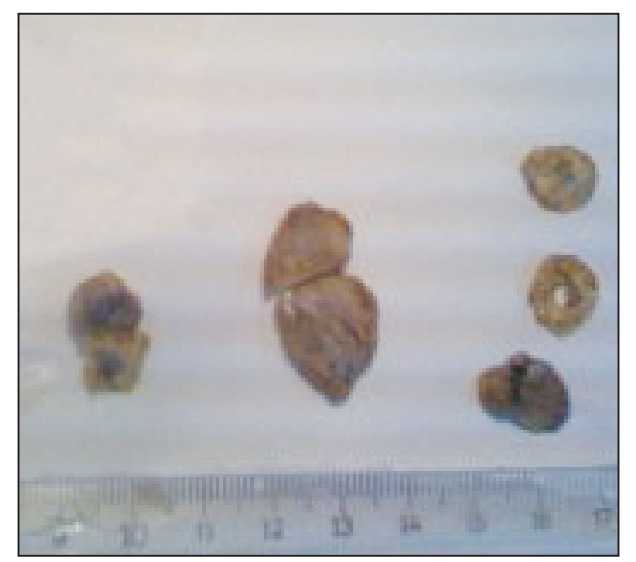

Figure 2:

Macroscopic view of the excised pulmonary nodule.

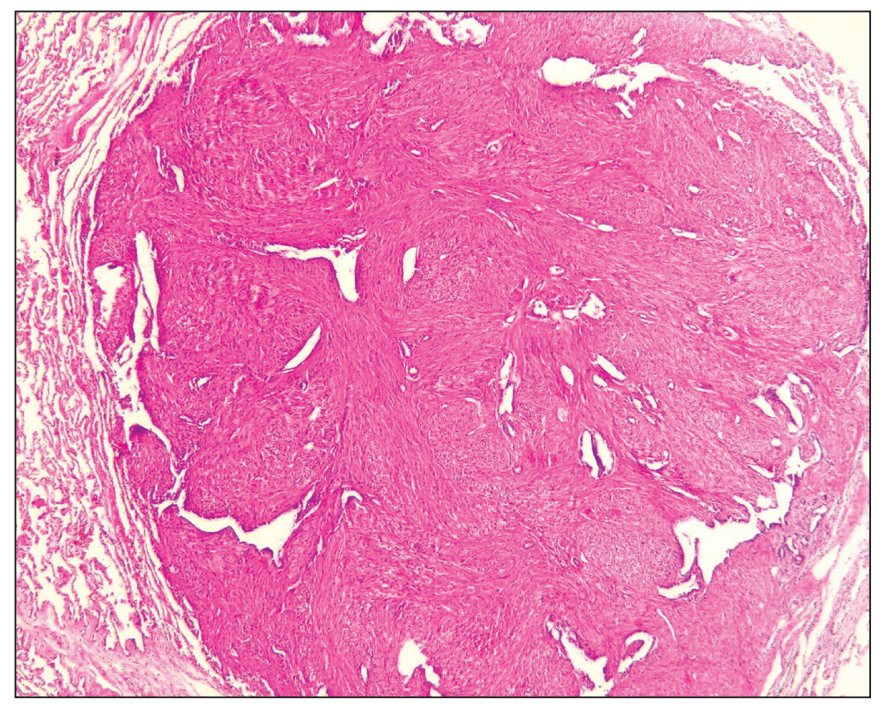

Figure 3: The specimen showed a well-circumscribed nodule with compressed adjacent lung parenchyma having interlacing bundles of spindle cells (H\&E x200).

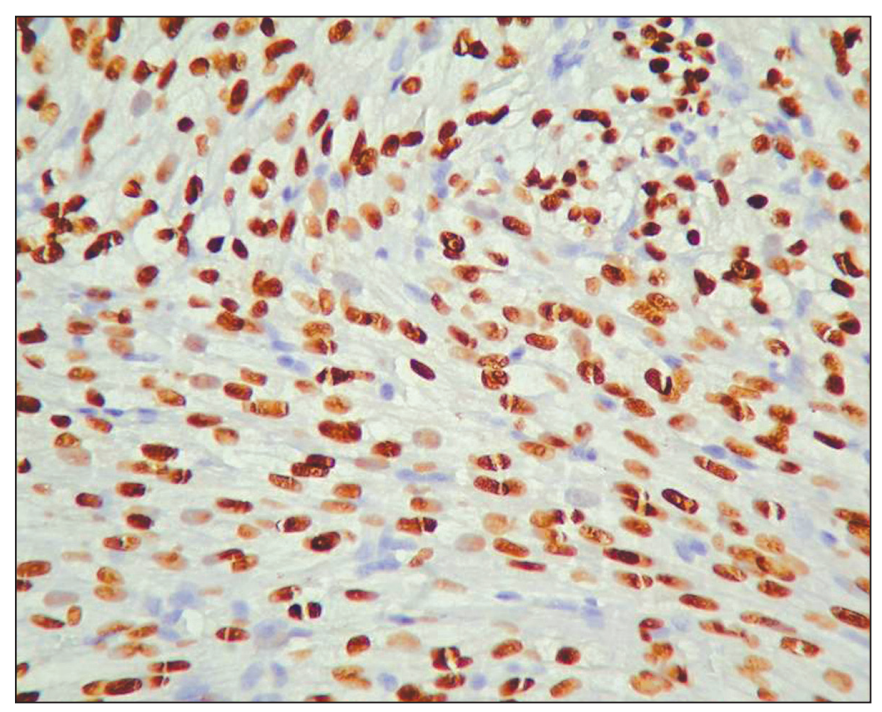

Figure 4: Wide nuclear ER expression in the smooth muscle cells (ER x400).

salpingo-oophorectomy was performed to complete the treatment. The previous lesion noticed in the right pelvic region was reported to be leiomyoma.

\section{DISCUSSION}

Benign metastasizing leiomyoma (BML) is a very rare condition that is predominantly seen in women during their reproductive years. BMLs are usually associated with uterine leiomyoma and may develop years after a hysterectomy or myomectomy (approximately 14.9 years). The average number of nodules is 6 with an average size of $1.8 \mathrm{~cm}$. Pulmonary lesions are bilateral in $70 \%$, unilateral in $17 \%$ and solitary in $13 \%$ of cases. The average survival after pulmonary resection is 94 months $(1,6)$. In our case, the patient had undergone a myomectomy 16 years earlier and total abdominal hysterectomy 14 years before the recurrence. A total of 5 nodules, the largest measuring $1.5 \mathrm{~cm}$, were excised from the right lung and a total of 6 nodules, the largest being $1.2 \mathrm{~cm}$ were excised from the left lung. This finding is similar to reported literature. We could not obtain paraffin blocks of previous specimens and hence were unable to recheck them.

The pathogenesis of BMLs is controversial. Various hypotheses on the histogenesis of these lesions have been suggested, which include: (i) Metastases of low grade and undetected leiomyosarcomas of the uterus; (ii) Smooth muscle proliferation in several organs, such as the lung and uterus resulting from an abnormal sexual hormone status; (iii) The last, and most accepted hypothesis, is the spread by lymphovascular dissemination of benign uterine leiomyoma cells. The theory of lymphovascular dissemination of uterine leiomyomas is based upon reports of spontaneous 
regression of pulmonary leiomyoma during pregnancy, absence of evidence of necrosis, and lack of mitotic activity $(1,7)$. Studies of the pulmonary and/or extra uterine nodules have revealed similar immunohistochemical, genetic and molecular characteristics to uterine leiomyomas (8-11). Vimentin, smooth muscle actin and desmin expressions, together with positive ER and PR is present in $80 \%$ of cases. There is no positive ER expression in extra uterine leiomyoma. There is $13 \%$ weak focal positive ER in LMS cases. In our case, vimentin, smooth muscle actin, desmin, ER and PR immunohistochemical expression were present. The Ki-67 proliferative index is low in BML cases. In two different studies the ratios were reported to be $2.3 \%$ and $2.9 \%$. In these studies, the Kİ-67 expression in LMS cases was $28.6 \%$ and $11 \%(1,9)$. In our study, the Ki-67 proliferation index was approximately $3 \%$. In a 3 case literature report, 2 cases showed monoclonality in the uterine and pulmonary tumors; while the third was noninformative. In the same study, the length of the telomere in the uterine and pulmonary tumors was found to be long, yet a longer telomere length was noticed in the other case. Meanwhile, deletion in the longer arm of chromosomes 19 and 22 is frequently noticed (10). With in situ hybridization techniques using mir-221 micro-RNA analysis 13 out of the 15 LMS cases showed expression, while there was no expression in the $10 \mathrm{BML}$ and 8 leiomyoma cases. The study pointed out the use of these features in the differential diagnosis between BML and LMS (11). Usually diagnosis of pulmonary BML is made by open lung biopsy. In a 7 case literature report, diagnosis with cytology and transbronchial biopsy was inconclusive, while in 1 case diagnosis was made with tru-cut biopsy (12). In our case, transthoracic tru-cut was non diagnostic and hence open lung biopsy was used. There is no standardized treatment, thus medical (anastrozole, tamoxifen, raloxifene, progesterone and GnRH agonists) or surgical (bilateral oophorectomy) and hormonal manipulation together with general excision of the pulmonary nodules may be conducted $(1,4.5)$. In our case, bilateral salpingo-oophorectomy was used to block the estrogen release. The lesion in the paratubal region was diagnosed as leiomyoma. Metastases, sarcoidosis, inflammatory diseases, hamartoma, rheumatoid nodules, Wegener's granulomatosis and amyloidosis should be considered in radiological and clinical differential diagnosis (13). In our case, the thorax CT, radiological and clinical findings suggested metastases. The course of the disease depends on the state of the estrogen receptor (ER). Decrements in the pulmonary nodule size have been noticed after menopause, during pregnancy and hormonal contraception (14). With GnRH agonist, there has been a $50 \%$ decrement in the size of pulmonary nodules (15). In our case, after the nodule excision, there was no recurrence on the CT taken 12 months postoperatively.

\section{REFERENCES}

1. Kayser K, Zink S, Schneider T, Dienemann H, André S, Kaltner H, Schüring MP, Zick Y, Gabius HJ. Benign metastasizing leiomyoma of the uterus: Documentation of clinical,immunohistochemical and lectin-histochemical data of ten cases. Virchows Arch. 2000;37:284-92.

2. Galvin SD, Wademan B, Chu J, Bunton RW. Benign metastasizing leiomyoma: A rare metastatic lesion in the right ventricle. Ann Thorac Surg. 2010;89: 279-81.

3. Jo JH, Lee JH, Kim DC, Kim SH, Kwon HC, Kim JS, Kim HJ. A case of benign metastasizing leiomyoma with multiple metastasis to the soft tissue, skelatal muscle, lung and breast. Korean J of Intern Med. 2006 ;21:199-201.

4. Rivera JA, Christopoulos S, Small D, Trifiro M. Hormonal manipulation of benign metastasizing leiomyomas: Report of two cases and review of the literature. J Clin Endocrinol Metab. 2004; $89: 3183-88$.

5. Clement-Duchene C, Vignaud JM, Regent D, Martinet Y. Benign metastasizing leiomyoma with lung cystic lesions and pneumothoraces: A case report. Respir Med. 2010;3:183-5.

6. Sapmaz F, Ergin M, Katrancioglu O, Gonlugur T, Gonlugur U, Elagoz S. Benign metastasizing leiomyoma. Lung. 2008;186: 271-3.

7. Awonuga AO, Rotas M, Imudia AN, Choi C, Khulpateea N. Recurrent benign metastasizng leiomyoma after hysterectomy and bilateral salpingo-oophorectomy. Arch Gynecol Obstet. 2008;278:373-6.

8. Egberts JH, Schafmayer C, Bauerschlag DO, Jänig U, Tepel J. Benign abdominal and pulmonary metastasizing leiomyoma of the uterus. Arch Gynecol Obstet. 2006;274:319-22.

9. Kwon YI, Kim TH, Sohn JW, Yoon HJ, Shin DH, Park SS. Benign pulmonary metastasizing leiomyomatosis: Case report and a review of the literature. Korean J Intern Med. 2006;21: 173-7.

10. Patton KT, Cheng L, Papavero V, Blum MG, Yeldandi AV, Adley BP, Luan C, Diaz LK, Hui P, Yang XJ. Benign metastasizing leiomyoma: Clonality, telomere length and clinicopathologic analysis. Mod Pathol. 2006; 19: 130-40.

11. Nuovo GJ, Schmittgen TD. Benign metastaszing leiomyoma of the lung: Clinicopathologic, immunohistochemical, and microRNA analyses: Diagn Mol Pathol. 2008; 17:145-50.

12. Abramson S, Gilkeson RC, Goldstein JD, Woodard PK, Eisenberg $\mathrm{R}$, Abramson N. Benign metastasizing leiomyoma: Clinical, imaging, and pathologic correlation. AJR Am J Roentgenol. 2001;176:1409-13

13. Rao AV, Wilson J, Sylvester K. Pulmonary benign metastasizing leiomyoma following hysterectomy. J Thorac Oncol. 2008;3: 674-6.

14. Nasu K, Tsuno A, Takai N, Narahara H. A case of benign metastasizing loiomyoma treated by surgical castration flowed by an aromatase inhibitor, anastrozole. Arch Gynecol Obstet. 2009;279: 255-7.

15. Arif S, Ganesan R, Spooner D. Intravascular leiomyomatosis and benign metastasing leiomyoma: An unusual case. Int J Gynecol Cancer. 2006;16: 1448-50. 